
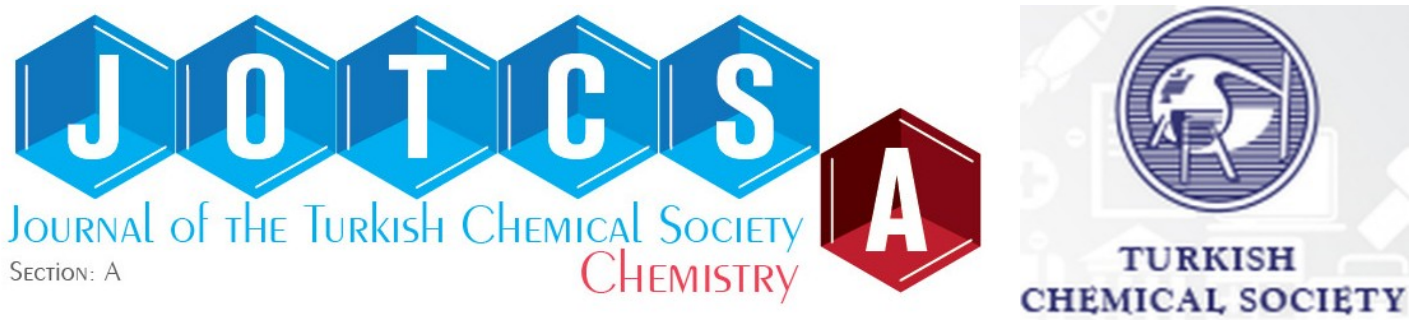

\title{
The production of antiviral - breathing mask against SARS-CoV-2 using some herbal essential oils
}

\section{Adem Önal'1* $\triangle D$, Oguz Özbek² $\triangle D$, Sama Nached ${ }^{3} \square$}

\begin{abstract}
${ }^{1}$ University of Tokat Gaziosmanpaşa, Natural Dyes Application and Research Center, 60250, Tokat, Turkey. ${ }^{2}$ University of Zonguldak Bülent Ecevit, Science and Technology, Application and Research Center, 67600, Zonguldak, Turkey.

${ }^{3}$ University of Tokat Gaziosmanpaşa, Faculty of Science and Arts, Department of Molecular Biology and Genetics, 60250, Tokat, Turkey.
\end{abstract}

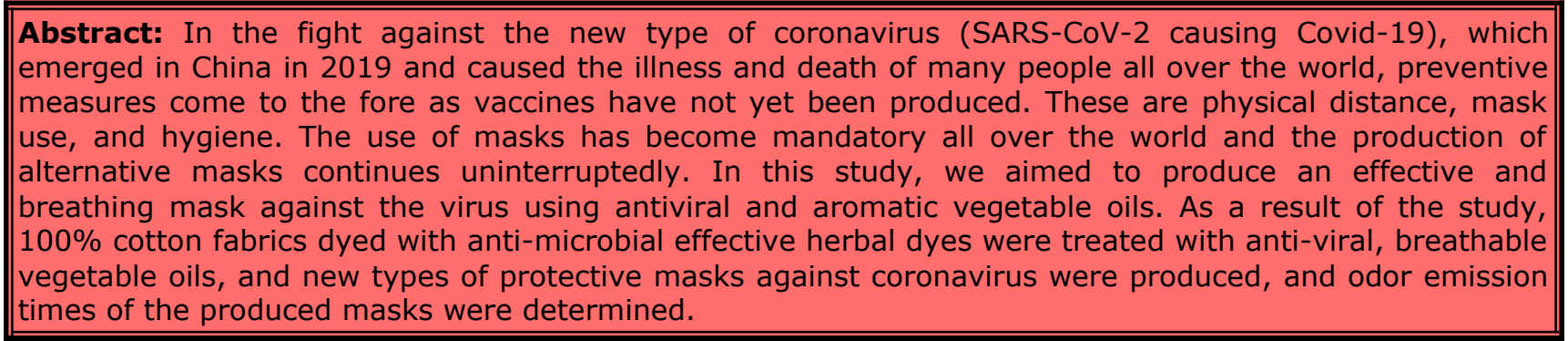

Keywords: Anti-viral plants, viral infections, mask, SARS-CoV-2, dyestuff.

Submitted: August 31 ,2020. Accepted: September 18, 2020.

Cite this: ÖNAL A, ÖZBEK O, NACHED S. The production of antiviral - breathing mask against SARS-CoV-2 using some herbal essential oils. JOTCSA. 2020;7(3):821-6.

DOI: https://doi.org/10.18596/jotcsa.788410.

*Corresponding author. E-mail: adem.onal@gop.edu.tr, Tel: +903562521616-3074.

\section{INTRODUCTION}

Coronaviruses (Latin: Orthocoronavirinae) are viruses that cause diseases in birds and mammals and are one of the two subfamilies of the Coronaviridae family. These viruses can cause respiratory infections in humans with several members, including MERS-CoV, SARS-CoV, and SARS-CoV-2 (causing COVID-19 (2019-nCoV)), along with a pathway compiled by common cold cases. Coronaviruses cause diarrhea in cows and pigs and respiratory diseases in chickens. They contain positive-polar, single-stranded RNA as their genetic material (genome). They are the viruses with the largest RNA genome detected to date, over 30 kilobases in length. The most distinctive feature of the virus, which has a size of 125 nanometers, is a similar protrusion around it. With this feature, it has been named coronavirus; because it resembles the crown of the sun (Latin: corona) under microscopy. No vaccine or specific antiviral drug has yet been developed against coronaviruses yet, including SARS-CoV-2. Symptomatic treatment, isolation, and various experimental applications are involved in the control of the disease. Hand washing, keeping distance, and not touching the face can be used to limit the spread of coronavirus infections (1-2).

\section{Coronavirus and Plants}

Starting at the end of 2019, herbal components effective on the new Coronavirus (SARS-CoV-2 (again an RNA virus) causing the disease named Covid-19), which peaked in 2020 and affected the whole world, has not been sufficiently studied since it is fairly new. For this 
reason, it is necessary to test the effectiveness of these components in the control of SARS-CoV-2 infections. According to the new study of Vietnamese scientists published in March 2020, garlic 'oil' has proven to be effective (natural antivirus) against SARS-CoV-2. This method which has been tested and yielded good results in the laboratory conditions is not yet available in the clinic. However, any herbal ingredient that relieves the symptoms of this viral infection has not yet been studied (3-8).

However, there are other scientific studies (also applied studies) effective against SARS (Severe Acute Respiratory Syndrome) virus (SARS-CoV), which is one of the old coronavirus varieties and some herbal essential oils have proven to be effective. One of these is a study by Lebanese scientists in 2008. According to this study, laurel (Laurus nobilis) oil, which is an important Mediterranean plant, was found to be effective against SARS-CoV. (In different scientific studies, other than laurel; indigo -Isatis indigotica with its new name Isatis tinctoria-, speedwell -Artemisia annua-, Lycoris radiata, Pyrrosia lingua (a type of fern), Lindera aggregate, licorice root are effective for SARS).

All of these studies are based on antiviral effectiveness. Antiviral extracts are known to not kill viruses but only inhibit them. However, it should be kept in mind that virucidal ingredients can be fully effective in viruses. In this sense, it should be stated again that there is no scientific applied study about any virucidal herbal component (number of in vitro-laboratory environment- virucidal studies is very small-). Viruses studied in most of these studies are viruses that mostly cause skin disorders (for example; Herpes simplex virus) rather than respiratory tract infecting-viruses (9-10).

Essential oils have been used in traditional medicine for many years to relieve viral respiratory symptoms in many parts of the world (11). In recent years, with the increase of publications examining the antiviral properties of essential oils, the mechanism of action of viruses affecting the upper respiratory tract such as influenza, SARS, and MERS has been revealed and the way for evidence-based applications is opened (12). Vimalanathan et al. conducted an in vitro study and the results of which show the efficacy of 10 minutes of vapor of eucalyptus (Eucalyptus globulus) and bergamot (Citrus bergamia) essential oils against virus infection. It was determined that the vapor of essential oils of cinnamon (Cinnamomum zeylanicum), lemongrass (Cymbopogon flexuosus), lavender (Lavandula officinalis), and geranium
(Pelargonium graveolens) showed a very strong antiviral effect against influenza (H1N1) virus within 30 minutes $(13,14)$.

\section{What are the standards of respirators?}

The US Centers for Disease Control (CDC) specifies the N95 respirators as part of the personal protective equipment (PPE) recommended in the Covid-19 and SARS guidelines. Europe, on the other hand, preferred the "Filtered face part" score (FFP) from EN standard 149:2001.

The features of known respirators are as follows;

- FFP2 filters have 94\% filter capacity

- N95 filters have 95\% filter capacity

- FFP3 and n99 filters have 99\% filter capacity

- N100 filters have $99.7 \%$ filter capacity

"Filter capacity" refers to what percentage of particles 0.3 micron or larger filters out (15).

\section{EXPERIMENTAL SECTION}

\section{Reagents and equipment}

Terry Cotton mask fabric was purchased from Toga Textile Company, Tokat-Turkey. Essential oils were provided from Cemre Herbal Company in 2020, Tokat, Turkey. These fabrics are light, durable, washable, do not cause sweating, and have air permeability. It is mostly used in the health sector. Distilled water was used for all steps. Extraction was performed using soxhlet apparatus. Color codes were determined by Pantone Color Guide. The wash-, crock- (wet, dry), and light- fastnesses of all dyed samples were established according to ISO 105-C06 and to CIS, and fastness values were determined by Atlas Weather-ometer, a Launderometer, and a 255 model crock-meter, respectively.

\section{Extraction of dyestuff}

Curcumin powder $(50 \mathrm{~g})$ was extracted in 5 liters of distilled water until colorlessness and used for dyeing of cotton fabric. Onion shells (250 g) was extracted in 5 liters of distilled water until colorlessness and then used for dyeing of cotton fabric (16).

\section{Dyeing of mask fabric}

Unmordanting dyeing method was applied for the dyeing of mask fabrics. For this purpose, Cotton (1 $\mathrm{m}^{2}$ ) fabric was dyed in the 5 liters of dye bath solution for $30 \mathrm{~min}$. at $70{ }^{\circ} \mathrm{C}$ at medium $\mathrm{pH}$, At the end of the dyeing period, the dyed fabric was removed, rinsed with distilled water, and dried.

\section{Dyeing mechanism}

The dyestuff in Allium cepa is Quercetin and the dyestuff in Curcumin longa is Curcumin as seen below (17) (Figure 1). 
<smiles>O=c1c(O)c(-c2ccc(O)c(O)c2)oc2cc(O)cc(O)c12</smiles>

Quercetin<smiles>[R]c1cc(/C=C/C(=O)CC(=O)/C=C/c2cc([R7])c(O)c([R7])c2)ccc1O</smiles>

$\mathrm{R}^{\prime}=\mathrm{R}^{\prime \prime}=\mathrm{H}$ : Curcumin

$\mathrm{R}=\mathrm{OMe} ; \mathrm{R}^{\prime}=\mathrm{H} ; \mathrm{R}^{\prime \prime}=\mathrm{H}$ : dimethoxycurcumin $\mathrm{R}=\mathrm{R}^{\prime}=\mathrm{R}^{\prime \prime}=$ OMe: 5-methoxycurcumin

\section{Curcumin}

Figure 1: Structure of Quercetin and Curcumin.

Quercetin and curcumin are bonded with hydrogen bonds to the oxygen atoms in the -OH groups of the cellulose molecules (Figure 2) and provide the fabric to be dyed.

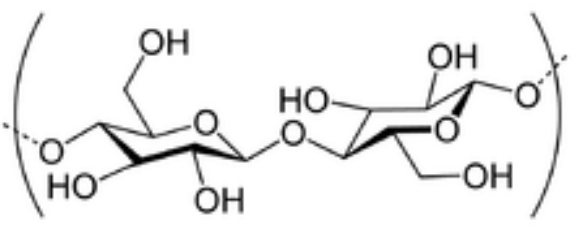

Figure 2: Structure of Cellulose.

\section{Treatment of mask fabric with essential oil}

For this purpose, the dyed fabrics using Curcumin longa and Allium cepa extracts were soaked with distilled water and treated with essential oils as given in Table 1. They were left to dry at room temperature. Later, odor emission times were determined (Table 2).

Table 1. Fastness values and color codes of dyed cotton mask fabric for Curcumin Longa and Allium Cepa.

\begin{tabular}{|c|c|c|c|c|c|c|}
\hline Method & Plant/dye & pH & Light & Wash & $\begin{array}{c}\text { Rubbing } \\
\text { (wet/dry) }\end{array}$ & Color code \\
\hline Unmordanting & $\begin{array}{l}\text { Curcumin Longa } \\
\text { (Curcumin) }\end{array}$ & 7.0 & $6 / 7$ & 5 & $5 / 5$ & $\begin{array}{l}\text { Pantone Yellow CS } \\
\mathrm{C}: 0 \mathrm{M}: 2 \mathrm{Y}: 100 \mathrm{~K}: 6\end{array}$ \\
\hline Unmordanting & $\begin{array}{l}\text { Allium cepa } \\
\text { (Quercetin) }\end{array}$ & 6.8 & $5 / 6$ & $4 / 5$ & $5 / 5$ & $\begin{array}{l}\text { Pantone } 1235 \mathrm{CS} \\
\mathrm{C}: 0 \mathrm{M}: 27 \mathrm{Y}: 93 \mathrm{~K}: 0\end{array}$ \\
\hline
\end{tabular}

The odor emission times of mask fabrics dyed with onion shell and curcumin longa are given in Table 2.

Table 2. Odor emission times of dyed mask fabrics.

\begin{tabular}{cccc}
\hline Dye plant & Plant oil & Number of oil drops & $\begin{array}{c}\text { Odor emission } \\
\text { period (h) }\end{array}$ \\
\hline Onion Shell/Curcumin & Lavender + clove & $3+3$ & 48 \\
Onion Shell/Curcumin & Lavender + Thymus & $4+4$ & 288 \\
Onion Shell/Curcumin & Mint + Thymus & $2+2$ & 120 \\
& Mint + Thymus & $3+3$ & 160 \\
Onion Shell/Curcumin & Clove + Thymus & $2+2$ & 288 \\
Onion Shell/Curcumin & Clove + Thymus & $3+3$ & 288 \\
Onion Shell/Curcumin & Juniper & 4 & 24 \\
Onion Shell/Curcumin & Juniper & 6 & 24 \\
Onion Shell/Curcumin & Rosemary & 6 & 24 \\
Onion Shell/Curcumin & Mint & 6 & 28 \\
Onion Shell/Curcumin & Thymus & 6 & 288 \\
Onion Shell/Curcumin & Clove & 6 & 24 \\
Onion Shell/Curcumin & Rosemary & 4 & 24 \\
Onion Shell/Curcumin & Mint & 4 & 288 \\
\hline
\end{tabular}

When the results are examined in Table 2, it is seen that the vegetable oils with the longest odor emission time are thyme and clove oils for each dyed cotton fabrics with both onion (Allium Cepa) 
and curcumin (Curcumin Longa). A single and double mixture of thyme and clove oil mixtures have $288 \mathrm{~h}$ of odor emissions. This result can be considered as an advantage pointing to the higher antiviral properties of thyme oil. The odor emission time was determined as $48 \mathrm{~h}$ for a mixture of (lavender + clove) oil. Mint, rosemary, and juniper oils provide odor emission for $24 \mathrm{~h}$ only. Masks dyed with Curcumin Longa and Allium Cepa extracts are given in Figure 3.

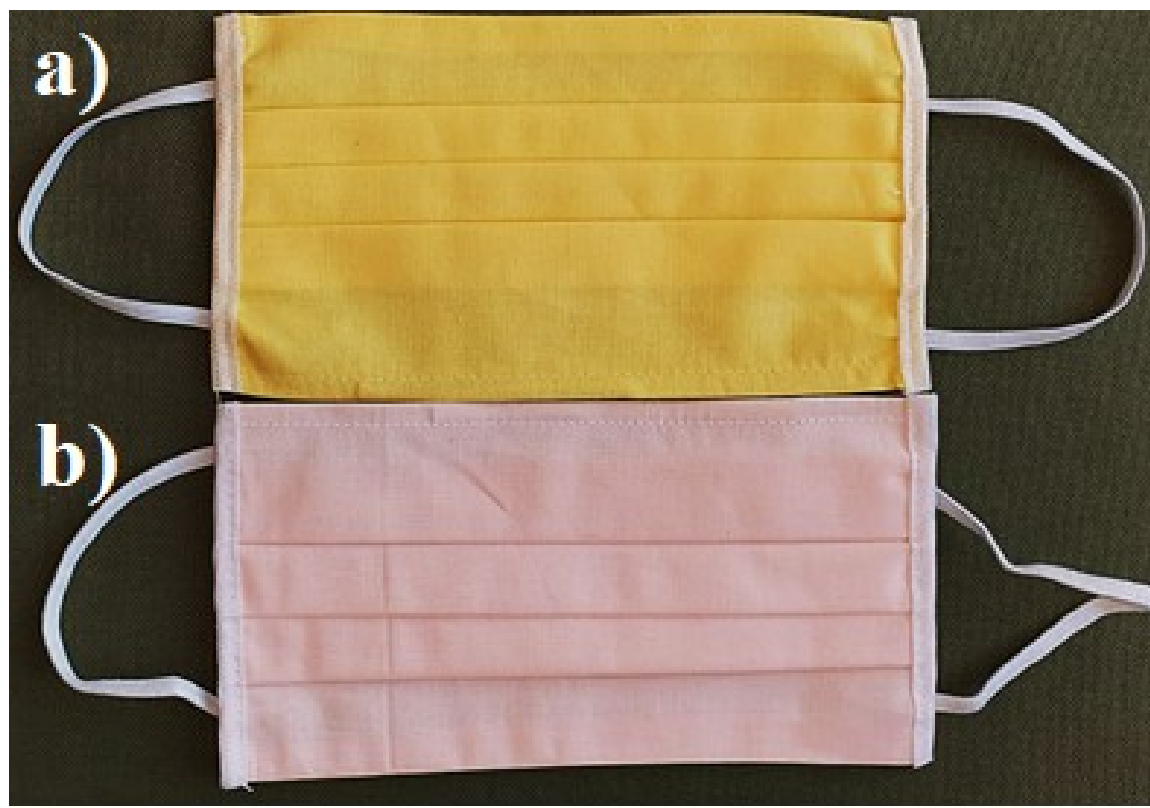

Figure 3: Masks dyed with Curcumin Longa (a) and Allium Cepa (b) extracts.

\section{CONCLUSION}

In this study, terry cotton fabric following the medical standards was dyed with antimicrobial Curcumin Longa and Allium Cepa extracts to protect against the highly contagious, and a new, lethal type of coronavirus (SARS-CoV-2 causing the disease termed Covid-19), which emerged in China in 2019 and soon caused a pandemic. Later, antiviral and breath-opening properties were provided by interacting with antiviral and breath-opening vegetable oils. The odor emission times of the masks were determined. The longest odor emission was achieved with the combination of thyme and clove oil. The masks we produced are wired, washable and rechargeable with vegetable oils.

In some countries, different masks are produced to protect against coronavirus infection. Some of these masks contain photocatalytic titanium dioxide, and also silver nitrate is added to some. Some entrepreneurs have produced 3-layer masks coated with herbal solutions. It has been featured in the media that self-cleaning masks are produced from carbon fibers. We aimed to contribute to the pandemic period by producing a new type of mask that is protective against SARS-CoV-2 infection. After this stage, it is necessary to examine the effects of these masks on patients in an interdisciplinary study. Further investigations are still going on.

\section{ACKNOWLEDGMENTS}

The authors would like to thank Tokat Maturation Institute for contribution.

\section{REFERENCES}

1. Yücel B, Görmez A. Sars-Corona Virus Overview. Turkish Journal of Applied Sciences and Technology. 2019;2(1):32-9.

2. Bozler MA. Recommendation of uygur medicine products for novel coronavirus (COVID19). Journal of Integrative and Anatolia Medicine. 2020;1(2):21-8.

3. Astani A, Reichling J, Schnitzler P. Comparative study on the antiviral activity of selected monoterpenes derived from essential oils. Phytotheraphy Research. 2009;24(5):673-9. Doi: 10.1002/ptr.2955.

4. Brochot A, Guilbot A, Haddioui L, Roques C. Antibacterial, antifungal, and antiviral effects of three essential oil blends. Microbiologyopen. 2017;6(4):e00459. Doi: 10.1002/mbo3.459.

5. Cinatl J, Morgenster B, Bauer G, Chandra P, Rabenau H, Doerr HW. Glycyrrhizin, an active component of liquorice roots, and replication of 
SARS-associated 2003;361:2045-6. coronavirus.

Lancet. 6736(03)13615-X.

6. Elaissi $A$, Rouis $Z$, Salem NAB, Mabrouk $S$, Salem YB, Salah KBH, Aouni M, Farhat F, Chemli R, Harzallah-Skhiri F, Khouja ML. Chemical composition of 8 eucalyptus species' essential oils and the evaluation of their antibacterial, antifungal and antiviral activities. BMC Complementary and Alternative Medicine. 2012;12:81. Doi: 10.1186/1472-6882-12-81.

7. Garozzo A, Timpanaro $R$, Bisignano $B$, Furneri PM, Bisignano G, Castro A. In vitro antiviral activity of melaleuca alternifolia essential oil. Letters in Applied Microbiology. 2009;49:806-8. Doi: 10.1111/j.1472-765X.2009.02740.x.

8. Li $S$, Chen $C$, Zhang $H$, Guo $H$, Wang $H$, Wang L, Zhang X, Hua S, Yu J, Xiao P, Li R, Tan X. Identification of natural compounds with antiviral activities against sars-associated coronavirus. Antiviral Research. 2005;67:18-23.

9. Lin C, Tsai F, Tsai C, Lai C, Wan L, Ho T, Hsieh C, Chao PL. Anti-SARS coronavirus 3C-like protease effects of isatis indigotica root and plantderived phenolic compounds. Antiviral Research. 2005;68:36-42.

10.1016/j.antiviral.2005.07.002.

10. Loizzo $M$, Saab A, Tundis $R$, Statti $G$, Menichini F, Lampronti I, Gambari R, Cinatl J, Doerr $\mathrm{H}$. Phytochemical analysis and in vitro antiviral activities of the essential oils of seven lebanon species. Chemistry \& Biodiversity. 2008;5(3):46170. Doi: $10.1002 / c b d v .200890045$

11. Minami M, Kita M, Nakaya T, Yamamoto T, Kuriyama $H$, Imanishi $J$. The inhibitory effect of essential oils on herpes simplex virus type- 1 replication in vitro. Microbiology Immunology. 2003;47(9):681-4. Doi: 10.1111/j.13480421.2003.tb03431.x.
12. Thuy BTP, My TTA, Hai NTT, Hieu LT, Hoa TT, Loan HTP, Triet NT, Anh TTV, Quy PT, Tat PV, Hue NV, Quang DT, Trung NT, Tung VT, Huynh LK, Nhung NTA. Investigation into SARS-CoV2 resistance of compounds in garlic essential oil. ACS Omega. 2020;5(14):8312-20. Doi: 10.1021/acsomega.0c00772.

13. Usachev EV, Pyankov OV, Usacheva OV, Agranovski IE. Antiviral activity of tea tree and eucalyptus oil aerosol and vapour. Journal of Aerosol Science. 2013;59:22-30. Doi: 10.1016/j.jaerosci.2013.01.004.

14. Vimalanathan S, Hudson J. Anti-influenza virus activity of essential oils and vapor. American Journal of Essential Oils and Natural Products. 2014;2(1):47-53.

15. MacIntyrea $C R$, Chughtai AA. A rapid systematic review of the efficacy of face masks and respirators against coronaviruses and other respiratory transmissible viruses for the community, healthcare workers and sick patients. International Journal of Nursing Studies. 2020;108:103629. Doi: 10.1016/j.ijnurstu.2020.103629.

16. Onal A, Eser F, Bayrak S. Investigation of dyeing properties of different fabric species with alkanna orientalis root extract. Journal of Food Science and Engineering. 2017;7:213-20. Doi: 10.17265/2159-5828/2017.04.006.

17. Onal A, Yilmaz M, Eser F. Use of fermented dough extract in the dyeing of wool fabrics. Indian Journal of Fibre \& Textile Research. 2018;43:132-5. 
